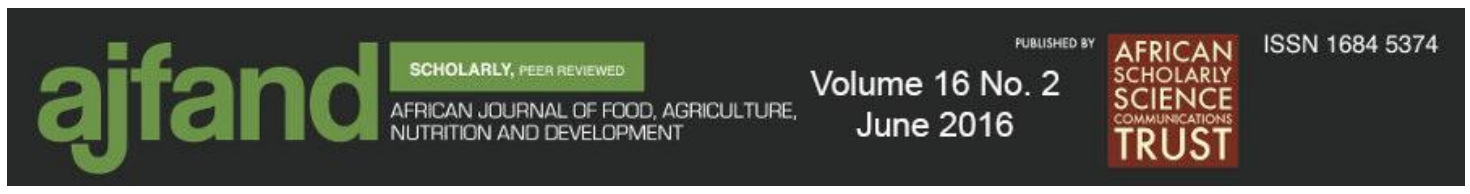

DOI: 10.18697/ajfand.74.12470

\title{
NUTRITION AND HEALTH STATUS OF HIV-INFECTED ADULTS ON ARVS AT AMREF CLINIC KIBERA URBAN SLUM, KENYA
}

$$
\text { Juma RJ }^{1^{*}} \text {, Kuria } E^{1} \text { and GO Rombo }{ }^{1}
$$

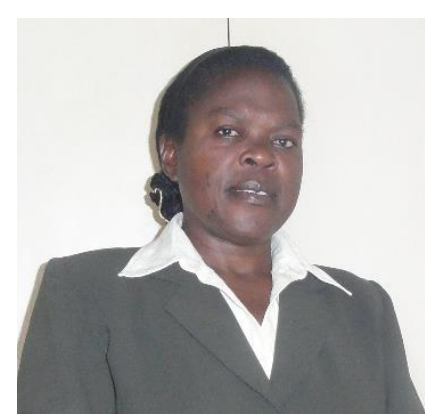

Rose Janet Juma

*Corresponding author email: rjuma20@yahoo.com AND/OR jan.juma1@gmail.com

${ }^{1}$ Kenyatta University, School of Applied Human Sciences, Department of Food, Nutrition and Dietetics P. O Box 43844-00100 Nairobi Kenya 


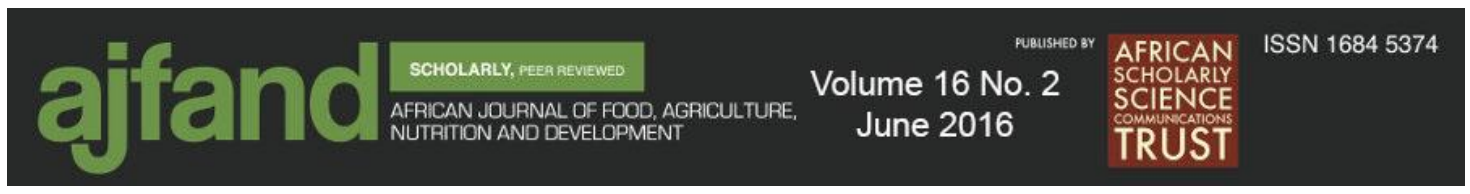

\section{ABSTRACT}

The health of people living with HIV and AIDS (PLWHA) is nutritionally challenged in many nations of the world. The scourge has reduced socio-economic progress globally and more so in sub-Saharan Africa (SSA) where its impact has been compounded by poverty and food insecurity. Good nutrition with proper drug use improves the quality of life for those infected but it is not known how PLWHA exposed to chronic malnutrition and food shortages from developing nations adjust their nutrition with use of Anti-Retroviral Drugs (ARVs). This study assessed nutritional status, dietary practices, and dietary management of common illnesses that hinder daily food intake by the patients and use of ARVs with food recommendations provided by the health care givers. A descriptive case study design was used to sample $120 \mathrm{HIV}$-infected patients using systematic sampling procedure. These patients sought health care from an urban slum, Kibera AMREF clinic. Data were collected by anthropometric measurements, bio-chemical analysis, semi-structured questionnaire and secondary data. The Statistical Package for Social Sciences (SPSS) and the Nutri-Survey software packages were used to analyze data. Dietary intakes of micro-nutrients were inadequate for $>70 \%$ of the patients when compared to the Recommended Daily Requirements. When Body Mass Indices (BMI) were used, only $6.7 \%$ of the respondents were underweight $\left(\mathrm{BMI}<18.5 \mathrm{~kg} / \mathrm{m}^{2}\right)$ and $9.2 \%$ were overweight $\left(\mathrm{BMI}>25 \mathrm{~kg} / \mathrm{m}^{2}\right)$, serum albumin test results (mean $3.34 \pm 0.06 \mathrm{~g} / \mathrm{dl}$ ) showed $60.8 \%$ of the respondents were protein deficient and this was confirmed by low dietary protein intakes. The BMI was not related to dietary nutrient intakes, serum albumin and CD4 cell counts ( $p>0.05)$. It appeared that there was no significant difference in BMI readings at different categories of CD4 cell count ( $p>0.05)$ suggesting that the level of immunity did not affect weight gain with ARV as observed in many studies from developed countries. Malnutrition was, therefore, evident among the $60.8 \%$ of the cases as identified by serum albumin tests and food intake was not adequate $(68 \%)$ for the patients as they ate once a day due to lack of food. National food and nutrition policy should incorporate food security boosting guidelines for the poor people infected with HIV and using ARVs.

Key words: Diet, Nutrition, HIV/AIDs, Serum albumin, CD4 cell counts 


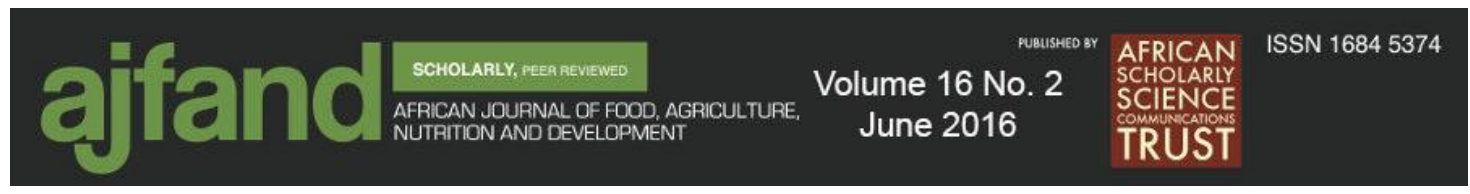

\section{INTRODUCTION}

Acquired Immune Deficiency Syndrome (AIDS) is a major health challenge to many nations. The scourge has scaled down social and economic progress in many countries and more so in the SSA where its impact has further been compounded by escalating poverty levels and food insecurity [1]. Studies from developed countries have shown that good nutrition with proper drug use improves longevity and productivity of life of those infected [1]. Little is known about how HIV-infected persons faced with chronic malnutrition and regular food shortages from a developing nation like Kenya adjust their dietary practices to attain good nutrition with use of ARVs.

By the end of 2007, the number of PLHWA was 33.2 million (1.1\% of global population) with 30.8 million adults aged 15 - 49 years [1]. Africa has $70 \%$ of global HIV and AIDS cases and to date there are 25 million adults and 2.6 million children living with HIV and AIDS in Africa [1]. Currently more than 1.2 million Kenyans are living with the HIVinfection [1]. The prevalence rate is $5.1 \%$ among Kenyan adults and deaths related to the scourge has significantly declined over the years; however, about 2.5 million Kenyans are living with the disease [1]. The adult female: male HIV prevalence ratio is almost 2:1 ( $8.3 \%$ and $4.9 \%$, respectively), which is higher than most parts of Africa [1]. Life expectancy in Kenya has reduced by 10 years to 50 years due to the scourge [1]. The total number of orphans below 14 years of age has risen to nearly 1.1 million over burdening the affected communities [1].

Much as access to anti-retroviral drugs continues to rise in poor developing nations of Africa, their use with good nutrition for chronically malnourished food insecure individuals is not fully known [2]. This study was timely because Anti-Retroviral Therapy (ART) programmes were yet to be established in Kenya and could make use of the generated descriptive data on dietary practices and nutrition for those using ARVs. Cases of patients taking ARVs with inadequate nutrition have been prevalent with many slum dwellers; hence the need for improvement in order to prolong quality life for people using ARVs [2]. The AMREF clinic in Kibera provides medical treatment, ARVs and Soya flour for the patients they register in order to help reduce malnutrition. The registered patients may have had good knowledge of nutrition with ARVs use as they were continuously taught by nutritionists. However, it was still not clear how they were managing drug intake with recommended food intake instructions, given the food insecurity and malnutrition challenges experienced in Kibera slums. The study, therefore, sought to generate insight into the afore-mentioned phenomenon.

\section{MATERIALS AND METHODS}

The study population was selected from HIV-positive females and males taking ARVs aged 15-49 years registered at the AMREF clinic for three years and above. The research design was a descriptive study. The design generated quantitative data that were put to statistical tests to increase the research reliability and better understanding of the phenomenon under study. 


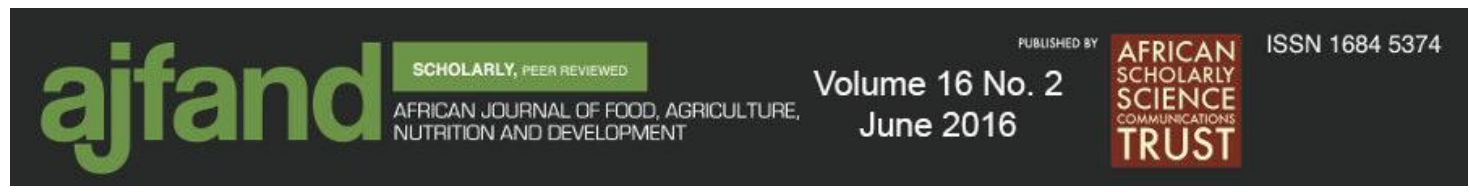

Ethical issues: A research permit was obtained from the Ministry of Education. The Kenya Medical Research Institute gave the ethical approval letter before the study was undertaken. Clinic administration and participants' consent was sought in writing and participation was purely voluntary. Anonymity of the respondents was maintained by use of code numbers for confidentiality.

\section{Sampling and sample size}

Kibera AMREF clinic was purposively identified for the study for its credibility and routine adult Anti-Retroviral Therapy programme. A sampling frame of 367 patients was registered for ARVs by the time of study. The research targeted 120 respondents selected systematically from the sample frame. A good sample population should be $10 \%$ to $30 \%$ of the entire population [3]. The study took $30 \%$ of the subjects as a reasonable representation of their population due to costs involved. A hundred and ten patients were to be the sample size but this was increased by $10 \%$ to a sample size of 120 to take care of natural attrition. From a list of randomly arranged names of 367 ARV patients in the clinic register, every third patient was picked for the study [4]. The first respondent from the first three in the register was selected by simple random sampling of folding three papers with their code numbers and picked by the researcher at random [4, 5]. Regular outpatient adults who were on ARVs for one year or more were included. Hospitalized, bedridden, or pregnant mothers were excluded from the study.

\section{Questionnaire}

A semi-structured questionnaire was used to determine demography, illnesses affecting food intake, dietary intakes and nutritional management of symptoms.

\section{Anthropometry}

Anthropometric measurements taken were weight and height, which were measured by using the weight-for-height machine (SECA 284 digital measuring station with automatic calibrations) that was available at the clinic. Each measurement was taken twice and averages recorded on the anthropometry sheet by the researcher and the assistants.

\section{Bio-chemical analyses}

Biochemical analysis was done on blood samples that were routinely collected for analysis in the clinic laboratory. Patients' CD4 cell counts were followed up on monthly basis and the nutrient analysis was incorporated into the procedure of the same blood for analysis.

\section{CD4 cell analysis}

The analysis was done by use of semi-automated clinical chemistry analyzer (Randon Micro-lab 300) with specific reagents and principles for serum albumin, total protein, cholesterol and haemoglobin.

Serum albumin test was based on its quantitative binding to the indicator 3, 3, 5, 5tetrabromo-m cresol sulphonephthalein (Bromocresol BCG). The albumin BCG complex absorbs maximally at $578 \mathrm{~nm}$ the absorbency being directly proportional to the concentration of albumin in the sample: Albumin is an end-point test. 


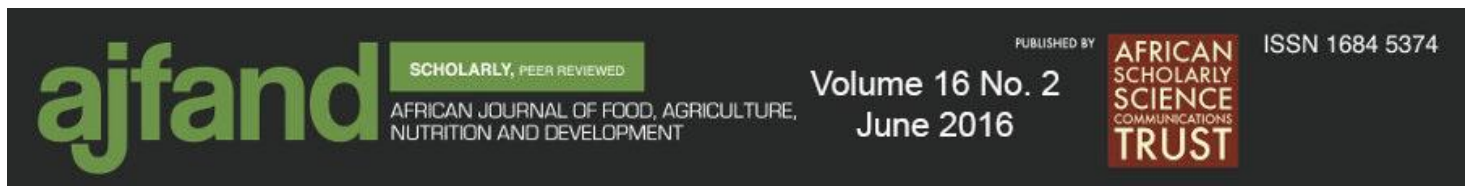

Total protein analysis used cupric- ions in an alkaline medium was used as it interacts with protein peptide bonds resulting in the formation of a coloured complex.

Cholesterol was determined after enzymatic hydrolysis on oxidation. The indicator quinoneimine was formed from hydrogen peroxide and 4-aminoantipyrine in the presence of phenol and peroxidase.

Hemoglobin test used coulter ACT series analyzer; the blood sample was hydrolyzed with drubkins solution (photonium ferricynide) to methaemoglobin that got converted by cyanide to stable haemoglobincyanide (HICN). The absorbance of HICN solution was read in comparison with the reference of HICN standard in the machine and the results were produced and recorded accordingly.

\section{Validity and Reliability of the Study Tools}

A pre-test on the semi-structured questionnaire and anthropometric tools was done twice at one-week intervals on five selected persons with HIV-status on ARVs who were not study respondents. Quantitative data from the two pre-test results were exposed to reliability test done by use of Pearson moment correlation coefficient(r) [5] and reliability of more than 0.6 was used for acceptability. The research tools were then revised and standardized in accordance with the pre-test results. Data analysis of the test data was done that guided the final data analysis.

\section{Data Collection Techniques}

Familiarization visits and study of secondary data from the respondents' medical records were done. Two research assistants (a nutritionist and a social worker from outside the study area) were trained for two days on data collection techniques, contents of the questionnaires and how to take anthropometric measurements. On the first encounter, respondents' consent was sought and the questionnaires were administered at the counseling room. Anthropometric measurements were taken at the same place with clothes removed. Heights and weights were measured simultaneously as the patient stood on the weighing scale, bare feet and upright with the back straight, buttocks and back of the head straight against the height board. The chin was put well at the right angle with the height board that was fixed at the back of the weighing machine [6]. Weight was read to the nearest kilograms and height read to the nearest $1 \mathrm{~cm}$. The data obtained was used to calculate BMI as an indicator of nutritional status [6].

The nutritional status, however, was counter-checked by bio-chemical analysis of blood samples of the same patients to determine the levels of serum total protein, albumin, cholesterol and hemoglobin. Biochemical analyses were done by semi-automated clinical chemistry analyzer (Microlab 300) with relevant reagents and specific principles. Blood analysis was factored into the regular routine blood check- ups. Data for CD4 and CD8 cell counts were obtained from secondary data routinely recorded in the clinic. Dietary intake assessment was done at respondents' residences. Preparations for this interview involved determination of various household measures used in the community and converting the measures into their metric versions to ease analysis. Though limited, information for the 24-hour recall was collected for one day to avoid respondent burden 


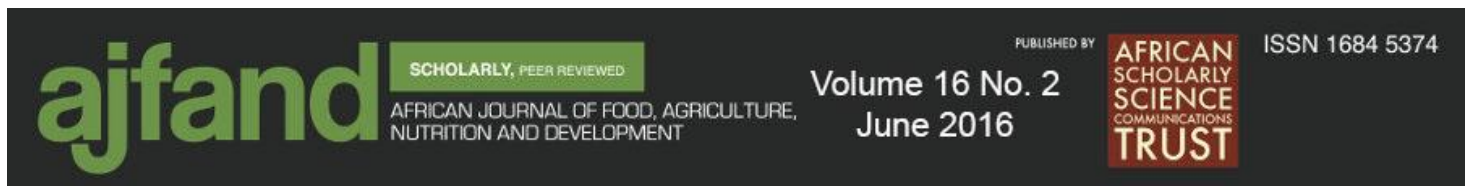

due to their poor health. Food consumption interviews were based on locally available foods and those that were considered to have positive or negative effect on immunity.

\section{Data analysis}

Data were edited, coded, and screened for accuracy before entering into Epi-data software. Coding was achieved by assigning each response a number, categorizing them and converting the data into numerical codes representing attributes. The Statistical Package for Social Sciences (SPSS, 2002: (R) 11.0, CHICAGO, IL.) was used to analyze the data and test the hypotheses. The 24-hour recall table results were analyzed separately by use of Nutri-Survey (For Windows (C) ERHARDT, 2005) computer software and food consumption patterns were analyzed by SPSS. The foods that were eaten more than four times a week were considered as Frequently eaten: while consumption of less than four times a week was viewed as; Not frequently eaten: and this was based on a normal serving per meal according to the community. The nutrient content of the foods was then extracted by use of Nutri-Survey software to determine levels of selected nutrients. The nutrients that were assessed were energy, protein, fat, vitamin $\mathrm{A}, \mathrm{B}_{2}, \mathrm{~B}_{6}, \mathrm{~B}_{12}, \mathrm{C}, \mathrm{E}$ and minerals magnesium, iron, zinc, iron, and selenium. Adequacies of nutrients were considered by comparing what the patients' intake was against recommended daily allowances (RDA) of the nutrients. The RDAs for the nutrients were obtained from the Kenyan Food Composition Table [7] and RDAs that were not there were obtained from American food composition tables. A cut-off point $75 \%$ of the RDA for the nutrients was used to indicate adequate or inadequate intakes [8].

The biochemical data were analyzed by the Randon in-built system in micro-lab analyzer that uses international reference standards. The data were then subjected to SPSS to determine means, frequencies and relationships among other variables. Normal ranges for each indicator were sought and those data, which were not falling in the normal ranges, were either high or low for normal body function CD4 and CD8 cell count values were analyzed by SPSS using the WHO organization cut-off points for the various stages of HIV infection.

Pearson correlation coefficient (r) was used to test for a relationship between body mass index and biochemical nutritional indicators as well as relationship between BMI and nutrient intake levels. Analysis of variances determined the significant difference of BMI at different levels of CD4 counts. The findings were summarized, organized and simplified in a systematic way with descriptive and inferential statistics.

Body mass index was graded according to the World Health Organization (WHO) classification of BMI [7]. The BMI was obtained from weight in kilograms divided by the square of the height in meters. Individuals with a BMI less than $18.5 \mathrm{~kg} / \mathrm{m}^{2}$ indicated under-nutrition and a high risk of illness; $18.6-25 \mathrm{~kg} / \mathrm{m}^{2}$ was normal; a BMI greater than $25 \mathrm{~kg} / \mathrm{m}^{2}$ indicated risk of overweight; and a BMI greater than $30 \mathrm{~kg} / \mathrm{m}^{2}$ indicated obesity with a high risk of diabetes and heart disease. Dietary recommendations for the various ARV regimens were determined by use of food and nutrition guide of the WHO and Gilead Pharmaceutical Company. 


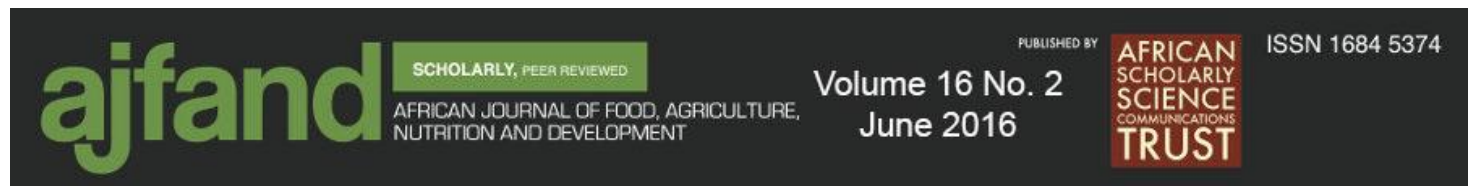

\section{RESULTS}

This research involved 120 respondents of whom $38 \%$ were male while $62 \%$ were female with age $35-44$ years being the majority $(43.3 \%)$. Half the respondents $(51.7 \%)$ were married and $69 \%$ of them had 4-6 persons per household. Most respondents $(98.3 \%)$ reported to have ever attended school and only $1.7 \%$ said they had never gone to school. Income was less than 1 dollar per day among $72.6 \%$ of them.

Inadequacies of vitamins $\mathrm{B}_{2}, \mathrm{~B}_{6}, \mathrm{~B}_{12}, \mathrm{C}$, folic acid and minerals magnesium, iron, selenium and zinc were evident in more than $70 \%$ of the subjects when their RDAs for a normal adult were considered. Meal patterns consisted of only one meal per day and the patients showed inadequate consumption of a variety of meals to maximize micronutrients' intake mainly due to lack of food. There was low intake of selenium (mean $=0.05 \pm 0.02 \mathrm{mg}$ versus RDA of $0.21 \mathrm{mg}$ per day). Deficiencies of vitamin $\mathrm{B}_{12}$ $(0.54 \pm 0.21 \mathrm{mg}: \mathrm{RDA}=1.00 \mathrm{mg})$, zinc $(5.14 \pm 1.27 \mathrm{mg}: \mathrm{RDA}=11 \mathrm{mg})$ and magnesium (223.50 $+34.7 \mathrm{mg}: \mathrm{RDA}=390 \mathrm{mg})$ were recorded. Vitamin A intakes on the other hand, were adequate for $83.3 \%$ of the patients with mean intake $=994.41 \pm 15.74 \mu \mathrm{gms}$ and RDA $=1000$ ugms. It was also noted that Vitamin A intake was boosted by monthly consumption of supplements (200,000 IU). Protein, energy and fat were inadequate for nearly half the population studied. Energy intake was below RDA by more than $150 \%$ (930.10+120.87kcal: 2700kcal RDA).

Majority (97.5\%) of the population purchased their food from the local markets and the respondents did food preparation for themselves. One respondent confessed that when sick she could not do anything and if not assisted could stay hungry for some time until she got well (Personal interview Kianda, Kibera: 2005). Carbohydrates were mainly cereals like maize meal, rice, millet, and bread. Ugali from maize meal was the most consumed by $62.5 \%$ of the respondents per week while $32.5 \%$ of the patients took millet porridge per week and $26.6 \%$ were able to consume bread more than 4 times a week. Protein sources were mainly pulses and high quality proteins such as milk, eggs, meat and fish were rarely consumed. Milk was consumed daily among 35.9\% of the respondents and most of it was being purchased as skimmed milk. Vegetable and fruit consumption were generally poor, though, bananas, oranges and mangoes were the most commonly accessed fruits among the respondents. More than two thirds (69.2\%) of the patients ate fruits only sometimes per week but not sure how many times. The low scores of vital vitamins $\mathrm{E}, \mathrm{B}_{2}$, folic acid $\left(\mathrm{B}_{9}\right)$ and $\mathrm{C}(<50 \%)$ by 24 hour recall also reflected this phenomenon. Consumption of oranges and lemons were fair for $52.3 \%$ and $41.4 \%$, respectively.

The consumption of traditional vegetables was also inadequate for the majority $(77.5 \%)$ and it was determined that vegetables like kale, spinach, cabbages and carrots were most commonly consumed as opposed to traditional vegetables like spider weed (saga), pigweed (amaranthus), black night shade (managu) and crotoleria spp. (mito). Some $(67 \%)$ respondents reported non-affordability of traditional vegetables as the reason why they could not eat them. Consumption of herbs and spices was rare among more than $74 \%$ of the respondents. Garlic seemed to be a preferred herb compared to others and was consumed daily by $26.7 \%$ of the respondents even though ginger and coriander (dania) were also commonly consumed. Among the caffeinated drinks that negatively 


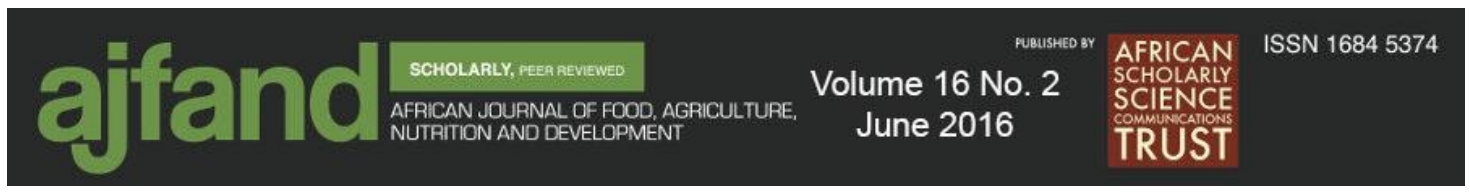

affect immunity, tea was taken frequently by $67.5 \%$ of the patients. Almost all (99\%) of the patients never took alcohol and coffee as expected from HIV patients taking medications. Fluid intake was in form of water (93.2\%), soup (17.5\%) and porridge $(55.8 \%)$. Cooking oils on the other hand, were used by $50.5 \%$ of the respondents daily while almost half used cooking fat.

The BMI results showed that majority of the respondents $(84.2 \%)$ had normal status, some $(9.2 \%)$ were overweight while only $6.7 \%$ of the respondents were underweight $(\mathrm{BMI}<18.5)$, (Figure 1).

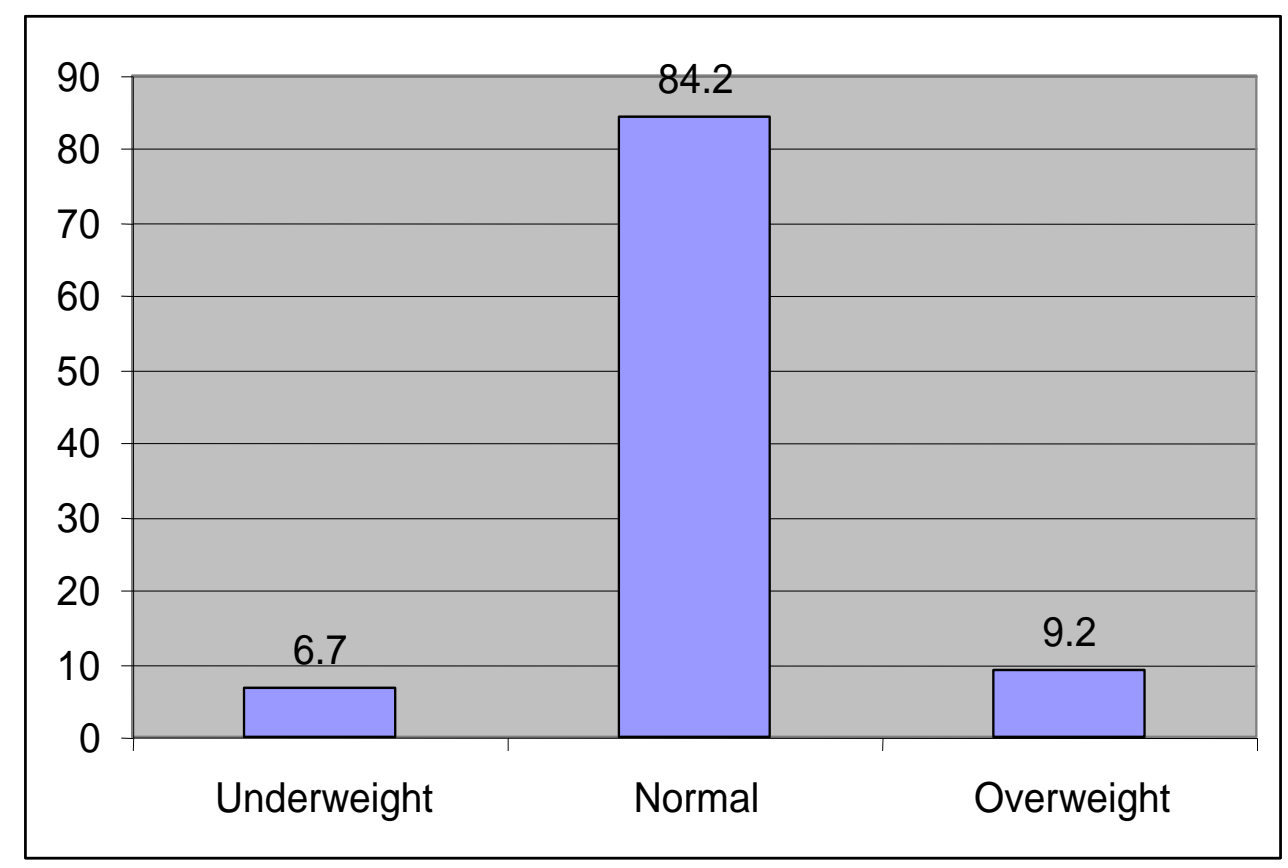

Figure 1: Body mass index for PLWHA at AMREF clinic in Kibera

More females were underweight (4.2\%) than males (2.5\%) and overweight problem was seen in many males $(5.8 \%)$ than females $(3.3 \%)$. These differences were, however, not significant $(\mathrm{P}>0.05)$ with independent $\mathrm{t}$-tests. Respondents who were non-compliant to food and drug instructions had significantly higher body mass indices compared to their compliant counterparts $(\mathrm{p}=0.048)$.

Serum albumin tests showed a mean of $3.37 \mathrm{~g} / \mathrm{l}(\mathrm{SD}=0.54)$ which was low and percentage results showed that $60.8 \%$ of the respondents had serum albumin scores below the normal values. Only $39.2 \%$ patients had normal ranges of serum albumin.

The CD4 cell counts below 409mmol/1 were considered low, a range of 410-1590 $\mathrm{mmol} / \mathrm{litre}$ was normal and those above 1590 were considered high. This study revealed that $54.2 \%$ of the respondents had their CD4 count below $410 \mathrm{mmol} / 1$ and $45.8 \%$ of the respondents had normal CD4 ranges $(410-1590 \mathrm{mmol} / 1)$. The mean CD4 cell count (326mmol/litre) was also low compared to the normal range of between 410-1590 $\mathrm{mmol} / \mathrm{litre}$ for a normal adult (Table 3 ). 
This study also established the extent to which patients from a slum set-up were following the best nutritional practices for drug use. Majority of the patients (73\%) seemed to have used the drugs for more than 1 year and only $27 \%$ had been on the drugs for exactly one year. Basing investigation on the majority drug combinations \{Zerit (Stavudine), Epivir (Lamivudine or 13TC) and Nevirapine (Viramine) \}, which was being taken by most PLWHA in the clinic, it was found that $39.2 \%$ of the patients were following the required food timing instructions but the rest $(52.5 \%)$ were not adhering to the recommended food intake instructions. Those who did not adhere to the instructions when asked the reason for non-adherence, more than half $(68 \%)$ cited unavailability of food as one reason why they could not time the drugs with food. A patient confessed "I am unable to follow instructions because these drugs require good eating but sometime the food is not available, what do I do?, I just take them on an empty stomach." (Personal interview at Kibera Laini Saba, 2005). Some respondents (12\%) gave late food preparation by their spouses as their main reason for not following instructions and $11 \%$ said they did experience nausea and vomiting that prevented them from taking drugs as instructed.

\section{DISCUSSION}

Patients with HIV infection are expected to increase their food consumption with balanced meal patterns of 3-4 times a day [9]. Though increasing protein intake is not well understood by some researchers, studies from developed nations have reported that protein and energy intake should be in excess even for symptom free cases [10]. A variety of foods is needed in order to avail high amounts of macro and micro-nutrients that are continuously being lost through urine, cachexia and other metabolic disorders that accompany the disease $[11,12]$. The low intakes among $70 \%$ respondents for protein, energy and key micronutrients were expected because the meal pattern was composed of one meal per day with low quantities of food escalated further with limited variety. Deficiencies of vitamin $\mathrm{B}_{12}$, zinc and magnesium has been associated with decline in CD4 cell counts and further depletion of immune system [13]. Adequate vitamin A intakes that were analyzed did mean that HIV-infected patients were adequate in the nutrient since they are expected to consume more above RDA as research suggests [14]. Low intake of selenium is a risk for mortality as it significantly correlates with activities that balance immune system [15]. The low selenium consumption correlated significantly with the low serum level indicating that more than half $(60.8 \%)$ were malnourished. Many reports $[16,17]$ confirm that intakes of nutrients correlate positively with blood serum albumin and, therefore, albumin test is a strong indicator of nutritional status especially for the chronically ill patients. Lack of money to buy food featured prominently as a hindrance to adequate purchase and consumption of food as seen in $69.2 \%$ of the subjects. Food sources for the residents were basically through purchase, a finding that was not surprising. With many of the respondents earning less than one dollar per day, which was to cater for all the essential basic needs, adequate nutrition was highly compromised. High and normal BMI is explained further by some studies that it could be due to elevated lipid abnormalities (lipodystrophy) [16, 17]. Majority of the respondents $(84.2 \%)$ though malnourished, had normal BMI and this was in agreement with reports that ARVs may cause weight gain in many patients but the weight is not due 


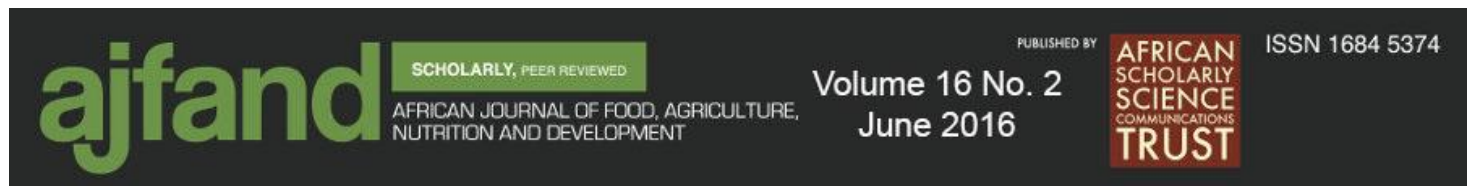

to growth in cell mass but rather to fat accumulation and water retention $[18,19]$. The studies further elaborated that there is always abnormal synthesis of fat and decrease in triglycerides for the patients on ARVs. Body mass index (BMI) results on further scrutiny did not have any relationship with nutrient intake, a case similar to a study by Wynn and Wynn [20] on HIV-patients in the USA. Low serum protein among 60.8\% subjects was a sign of protein deficiency even if total protein test results were positive and similar observations are recorded in many studies from USA and Britain [21, 22]. Body mass indices at different ranges of CD4 cell counts were also not significantly different and this affirmed reports that ARVs improve quality of life for many HIV-patients irrespective of their CD4 cell count (immunity) [23].

\section{CONCLUSION}

The study concluded that there was malnutrition (60.8\%) among the HIV-patients on ARVs when serum albumin was tested even though their BMIs were normal. Further assessment on food intakes revealed that the malnutrition was due to low food intake and low food purchasing power (69.2\%). Most of the subjects $(97.5 \%)$ were relying on purchased food that influenced $52.5 \%$ of the patients not to adhere to food and drug instructions, with inadequate nutrients of concern being protein, energy and micronutrients for $70 \%$ of the subjects.

\section{RECOMMENDATIONS}

Though establishment of ART programmes have reduced death significantly in Kenya, weight control may be a health challenge to mitigate upon in future. Comprehensive nutritional assessments and food security- boosting initiatives alongside other health care and socio-economic strategies are pivotal in improving longevity and quality of life for PLWHA using ARVs in a slum set up. Other recommendations for various stakeholders are as follows: Provision of ARVs with foods rich in immune boosting macro and micronutrients for people on ARVs by the health sector and biochemical analysis of serum protein is important for HIV positive individuals since it gives the real nutrition status as opposed to BMI for PLWHA. Nutritionists should prescribe diet plans of locally available foods to each patient on ARVs to facilitate better drug utilization. The agriculture sector needs to initiate simple food security projects with nutrient dense foods for HIV- challenged families in urban slums. 


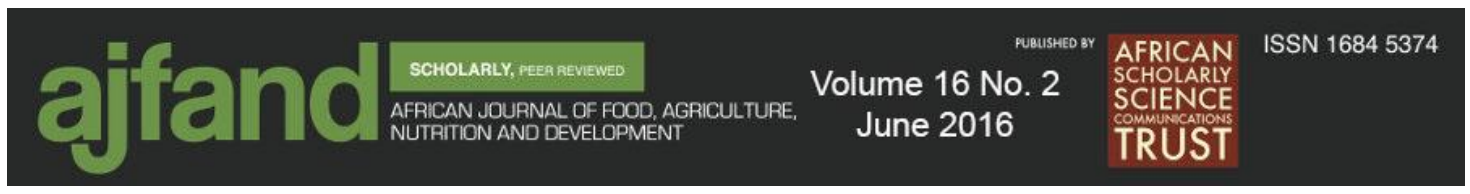

TABLES OF THE RESULTS

Table 1: Biochemical nutritional indicators of HIV-infected patients using ARVs at AMREF clinic Kibera

\begin{tabular}{lccccc} 
& \multicolumn{5}{c}{$\mathbf{N = 1 2 0}$} \\
\hline Indicator & Mean & Sd & Status & $\mathbf{F}$ & $\%$ \\
\hline $\begin{array}{l}\text { Albumin } \\
\text { (g/l) }\end{array}$ & 3.37 & 0.54 & $<37$ & 73 & 60.8 \\
& & & $38-44$ & 47 & 39.2 \\
& & & & & \\
$\begin{array}{l}\text { Cholesterol } \\
(\text { mmol/l) }\end{array}$ & 3.25 & 0.86 & $<5.17$ & 108 & 90.0 \\
& & & $>5.18$ & 12 & 10.0 \\
$\begin{array}{l}\text { Haemoglobin } \\
\text { (g/dl) }\end{array}$ & 12.43 & 2.14 & $<11.0$ & 31 & 25.8 \\
& & & $11-13.0$ & 70 & 58.3 \\
& & & $>14$ & 19 & 15.8 \\
$\begin{array}{l}\text { T. Protein } \\
(\mathrm{g} / \mathrm{l})\end{array}$ & 82.20 & 9.34 & $<63$ & 1 & 0.80 \\
& & & $64-83$ & 83 & 69.2 \\
& & & $>84$ & 36 & 30.0 \\
\hline
\end{tabular}

N=120 Key: Sd- standard deviation, F-frequency

Table 2: Dietary Food intake of key Nutrients of PLWHA at AMREF clinic in Kibera

\begin{tabular}{ll|l|l|l|l}
\hline Nutrient & $\begin{array}{l}\text { No. with } \\
\text { adequate } \\
\text { dietary intakes }\end{array}$ & $\begin{array}{l}\text { \% with } \\
\text { adequate } \\
\text { intakes }\end{array}$ & $\begin{array}{l}\text { Mean } \\
\text { Intakes }\end{array}$ & Sd & RDA \\
Energy(Kcal) & 82 & 63.8 & 930.10 & 120.87 & 2700 \\
Protein (gms) & 67 & 55.8 & 33.10 & 2.23 & 47 \\
Fat (gms) & 76 & 63.3 & 37.11 & 7.06 & 73 \\
Vit.A (ugms) & 100 & 83.3 & 994.41 & 15.74 & 1000 \\
Vit.E(mgs) & 48 & 40 & 4.09 & 2.41 & 12 \\
Vit.B2(mgs) & 47 & 39.2 & 0.56 & 0.50 & 1.2 \\
Vit.B6 (mgs) & 22 & 18.3 & 0.85 & 0.81 & 1.2 \\
Folic (ugms) & 42 & 35 & 75.43 & 5.61 & 600 \\
Vit. C (mgs) & 44 & 36.7 & 89.83 & 6.29 & 150 \\
Mg (mgs) & 28 & 23.3 & 223.50 & 34.79 & 390 \\
Iron (mgs) & 20 & 16.7 & 7.44 & 4.35 & 20 \\
Zinc (mgs) & 24 & 20 & 5.14 & 1.27 & 11 \\
Vit.B12(mgs) & 26 & 21.7 & 0.53 & 0.21 & 1 \\
Selenium(mgs) & 21 & 17.5 & 0.05 & 0.02 & 0.21 \\
\hline Key: kcal-kilocal
\end{tabular}

Key: kcal-kilocalories, gm-grams, mg-milligrams, ugm-micrograms, Sd-standard deviation and RDA- Recommended Daily Allowances 


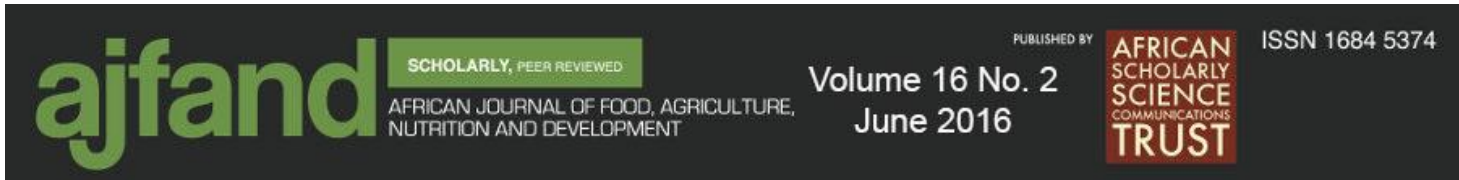

Table 3: CD4 and CD8 cell counts of HIV-patients on ARVs at Kibera AMREF clinic $(\mathrm{N}=120)$

\begin{tabular}{llllrr}
\hline $\begin{array}{l}\text { Indicator } \\
\text { (mmol/l) }\end{array}$ & Mean & Sd & Status & F & \% \\
\hline CD4 & 325.62 & 264.33 & $<409$ & 65 & 54.2 \\
& & & $410-1590$ & 55 & 45.8 \\
\hline CD8 & 857.28 & 564.82 & $<189$ & 5 & 4.2 \\
& & & $190-1140$ & 90 & 75.0 \\
& & & $>1141$ & 25 & 20.8 \\
\hline CD4/CD8 & 0.54 & 0.84 & $<5.17$ & 77 & 64.2 \\
& & & $>0.8-4.2$ & 42 & 35.0 \\
& & & $>4.3$ & 1 & 0.8 \\
\hline
\end{tabular}

Key: F- Frequency, Sd-standard deviation 


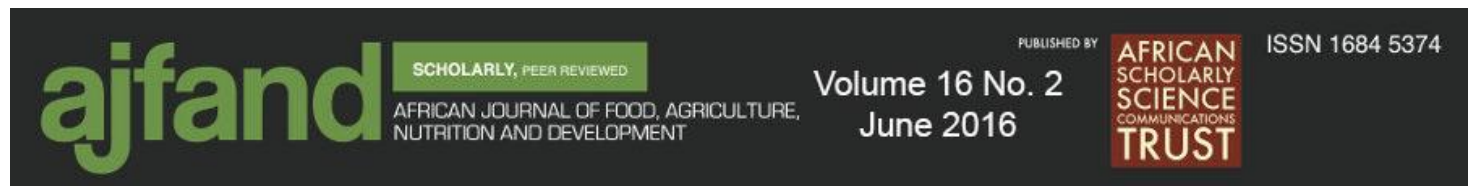

\section{REFERENCES}

1. United Nations AIDS (UNAIDS) Report on the Global HIV/AIDS epidemic: A joint publication by United Nations on HIV/AIDS pg. $14-26$ and $200-201$. Geneva, Switzerland.2008; 14-26 and 200-201.

2. Food and Nutrition Technical Assistance (FANTA) HIV/AIDS: A guide to nutritional care and support. Academy for Educational Development, Washington D.C. 2004.

3. Mugenda OM and AG Mugenda Research Methods: Qualitative and Quantitative Approaches. Acts Press, Nairobi, Kenya 2003.

4. Fisher AA, Lain JE, Stoeckel JE and JW Townsend Handbook for family planning operations research design. Second edition. Population Council. New York.1998.

5. Orodho JA Techniques of Writing Research Proposals and Reports in Education and Social Sciences. Masola Publishers. Nairobi, Kenya.2004.

6. Msamati BC and PS Igbigbi Anthropometric Profiles of Urban Adult Black Malawians. East Afri. Medl J. 2000; 41: 25.

7. Jaswant KS National food composition tables and the planning of satisfactory diets in Kenya. Kenya Government Printers Haille Selassie Avenue. 1993.

8. Takyi EN Dietary practices and dental caries in pre-school children in Ghana. East African Medical Journal. 1999; 100: 36.

9. National Aids Control Programme and Ministry of Health Kenya National Guideline for Nutrition and HIV/AIDS. 2005.

10. Agarwal N, Acevedo F, Leighton LS, Cayten CG and C Pitchmoni Predictive ability of various nutritional variables for mortality in elderly people. Am. J. Clin. Nutri. 1988; 48: 1173-8.

11. Kiure AK, Msamanga GI and NW Fawzi Nutrition and HIV -infection. AIDS in Africa. $2^{\text {nd }}$ Edition. New York: Klower Academic/Plenum publishers.1998; 419-435.

12. Hazel MR Nutritional Management of HIV/AIDS. State registered dietician. United Kingdom, Medscape HIV/AIDS. 2000.

13. Pronsky ZM, Meyer SA and C Fields-Gardner HIV Medication- Foodinteractions hand book (And so much more) $2^{\text {nd }}$ Edition-Internet.2001.

14. Fenton M Combating HIV with good nutrition. $12^{\text {th }}$ World AIDS Conference Geneva Reports. 1998; 1-14. 


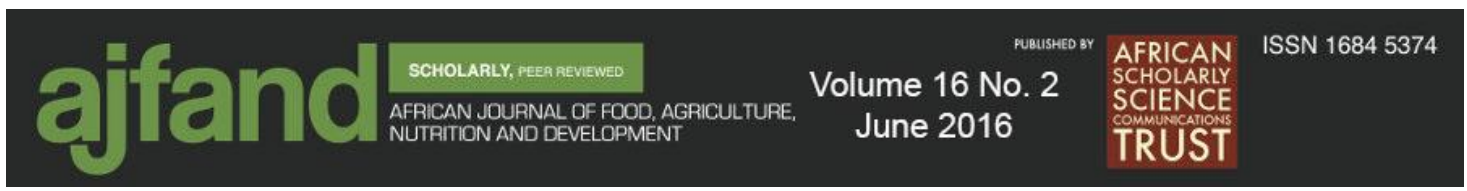

15. American Dietetic Association (ADA) Nutritional intervention in the care of persons with human immuno deficiency virus infection: position of the American Dietetics Association and Dieticians of Canada. American Dietetics Association and Dieticians of Canada. 2000; 100: 6:708 - 717.

16. Central Bureau of Statistics (CBS) [Kenya], Ministry of Health (MOH) [Kenya] and ORC Macro HIV-prevalence and associating factors. Kenya Demographic Health Survey (KDHS) 2003; 217-232.

17. Grunfeld $\mathbf{C}$ What causes wasting in AIDS? The New England Journal of Medicine. 1995; 333 (20):123 - 124.

18. Kotler DP Management of wasting syndrome in late HIV-infection: Significant advances in the treatment of cachexia. Columbia University College of Physicians and Surgeons St. Luke's- Roosevelt Hospital Center, New York.1995.

19. Lyn P Nutrients and HIV: Part 2 - Vitamin A and E, Zinc, B-vitamins and magnesium: Alternative Med. Re. J. 2000; 1: 38 - 51.

20. Wynn A and A Wynn Reducing waiting list for hospital admission. Community nutrition services reduce the need to for hospital beds. 9 View Reed, Highgate London N6. 4DJ. UK.1999.

21. Herman FR, Safran SE and KL Minaker Serum albumin level on admission as a predictor of death, length of stay and re-admission. Arch. Intern. Medicine. 1992; 152:125-130.

22. Mehta SH, Sterling TR, Asterborki J, Thomas DL and D Yhahor Serum albumin as a prognostic indicator for HIV disease progression. AIDs Research and Human Retrovirus J. 2006; 22 (1):14-15.

23. Kupka R Selenium status is associated with accelerated HIV-disease progression among HIV-1-infected pregnant women in Tanzania. Journal of Nutrition 2004; 134 (10): 2556-2560. 